\title{
Damage mechanisms and embrittlement kinetics in a $\beta$-rich Ti 17 alloy after long term aging
}

\author{
SASAKI Layla $^{\mathrm{a}^{*}}$, HENAFF Gilbert ${ }^{\mathrm{a}}$, ARZAGHI Mandana ${ }^{\mathrm{a}}$, VILLECHAISE Patrick ${ }^{\mathrm{a}}$, \\ HEMERY Samuel ${ }^{\mathrm{a}}$, DELFOSSE Jérôme ${ }^{\mathrm{b}}$ \\ a Pprime Institute UPR 3346 CNRS, ENSMA - Université de Poitiers, Department of Mechanics and Physics of Materials, 1 \\ Avenue Clément Ader, BP 40109, 86961, Futuroscope-Chasseneuil, France \\ b Airbus Group Innovations, 12 rue Pasteur, 92150 Suresnes, France
}

\begin{abstract}
$\underline{\text { Abstract }}$
The Ti 17 (Ti-5Al-2Sn-2Zr-4Mo-4Cr) alloy is used in the first stages of engine compressors, at temperatures up to $450^{\circ} \mathrm{C}$. However, its use in structural parts such as engine pylons is more prospective and raises the question of damage tolerance. As the engine pylon environment involves prolonged exposures to high temperatures, the impact of aging on mechanical properties has also to be taken in account.

In this work, the consequences of a long-term aging (up to $10000 \mathrm{~h}$ at $450^{\circ} \mathrm{C}$ ) on the mechanical resistance of a Ti 17 alloy are examined at different scales, from macroscopic fatigue crack growth tests to in-situ tensile tests performed on micro samples in a SEM. The detrimental effect of aging on the mechanical properties of the Ti 17 alloy was then discussed in the light of damage mechanisms analysis and embrittlement kinetics.
\end{abstract}

\section{$\underline{\text { Introduction }}$}

The Ti-5Al-2Sn-2Zr-4Mo-4Cr or Ti 17 alloy is considered as a $\beta$-rich titanium alloy [1] and has been first developed by General Electric Aircraft Engines in 1968 to be used in the first stages of GE90 engines used in Boeing 777 aircrafts [2]. The improved mechanical resistance of the Ti 17 alloy compared to the Ti-6Al-4V alloy constitutes one of its advantages, with a $25 \%$ increase in strength and a fracture toughness of $65 \mathrm{MPa} \mathrm{x} \mathrm{m}^{1 / 2}$ [3]. However, its operating temperature does not exceed $400-450^{\circ} \mathrm{C}$ [3], as the resistance to creep is not sufficient at higher temperatures and $\alpha$ alloys such as Ti-6242S are preferred [2].

The environment of use of such titanium alloys, whether being engine parts or structural parts like engine pylons, includes extended exposure to high temperatures. The issue of metallurgical transformations that could further alter the mechanical performances of such alloys becomes critical. Previous works have established the relation between precipitation of $\mathrm{Ti}_{3} \mathrm{Al}_{\text {, }}$ silicides and $\omega$ phases during aging and the embrittlement of the titanium alloys studied, expressed by a hardening of the material with increasing aging times [4-8] and an enhancement of fatigue crack growth rates compared to as-received samples $[7-10]$.

In a previous communication [10] an attempt to get a better understanding of the underlying mechanisms responsible for the embrittlement due to aging in a Ti 17 alloy has been initiated. The increases in fatigue crack growth rates at room temperature were linked to $\alpha$-lamellae decohesion markings, appearing once a critical value of the static component of the loading $\mathrm{K}_{\text {max }}$ was reached. These results are summarized in Figure 1. A fracture mechanism associated with a limited macroscopic plasticity has been proposed, based on strain localization induced by the precipitation of $\mathrm{Ti}_{3} \mathrm{Al}$ and $\omega$ phases at lamellae interfaces, along with the $\beta$ matrix softening. However, these conclusions were a reconstitution of the damage mechanisms after fracture, with no direct observations of such phenomena. 

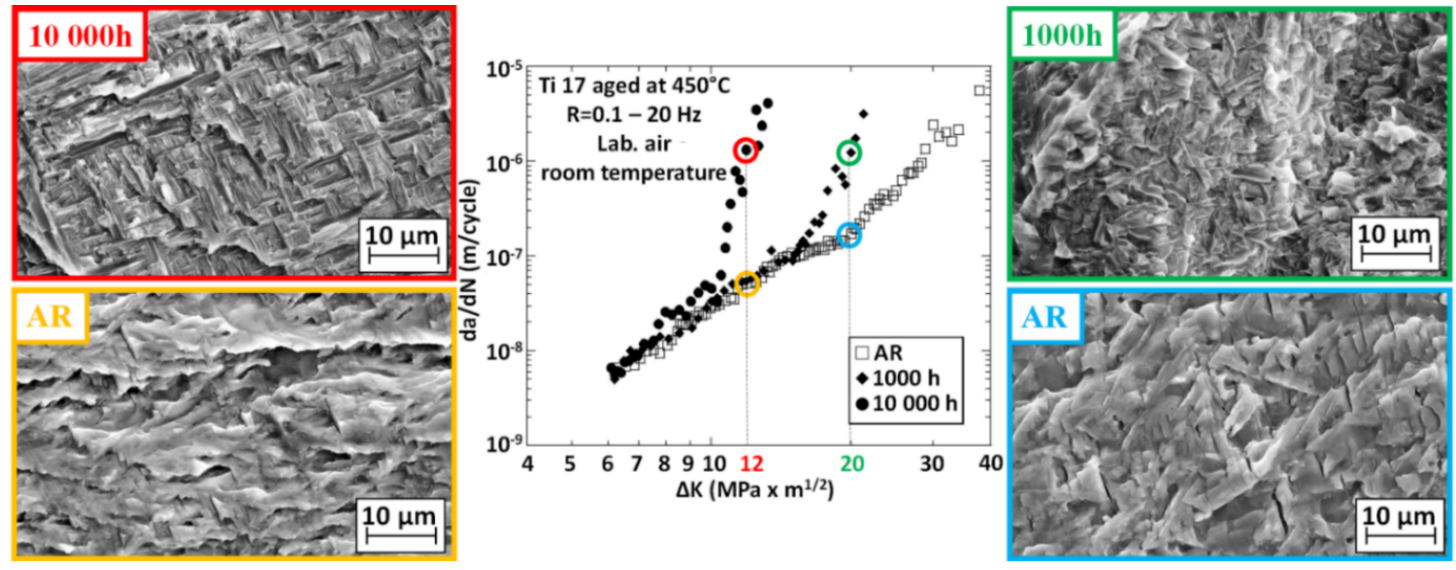

Figure 1: increases in crack growth rates observed in a Ti 17 alloy after aging at $450^{\circ} \mathrm{C}$, associated with the apparition of $\alpha$-lamellae decohesion markings absent on as-received (AR) samples [10]

The present communication will aim in getting a deeper insight into the embrittlement of the Ti17 alloy after aging, from two standpoints: the modification in damage mechanisms and the analysis of the embrittlement kinetics.

The analysis of fracture mechanisms will not only involve observations made at the scale of $\alpha$-lamellae on macroscopic fatigue crack growth samples, but also using a more delicate and local approach by means of in-situ tensile tests under SEM. Hemery et al. [11] studied the tensile behavior of a Ti-6Al-4V alloy aged $840 \mathrm{~h}$ at $500^{\circ} \mathrm{C}$ using similar in-situ tensile tests. A significant drop in elongation of aged specimen compared to the reference material was observed, as well as a minor yet remarkable increase in both yield and ultimate tensile stresses. The authors pointed out a sharper transition from elastic to plastic deformation in the aged case compared to the reference material, this phenomenon being closely linked to the $\mathrm{Ti}_{3} \mathrm{Al}$ precipitation. $\mathrm{Ti}_{3} \mathrm{Al}$ precipitates are believed to modify the activation order of slip systems responsible for plasticity, that proceed first on basal then prismatic slip systems for the reference material whereas after aging, the activation of both basal and prismatic slip systems occur simultaneously [11]. Based on previous observations that also reported an increased slip planarity due to $\mathrm{Ti}_{3} \mathrm{Al}$ precipitation [8], this work will aim to provide a closer observation of the plasticity development differences on asreceived and aged Ti 17 micro-samples, during the tensile test itself.

The embrittlement kinetics of the Ti17 alloy after aging will also be analyzed based on fatigue crack growth data of different aging conditions, in terms of time and temperature levels. Earlier studies [7-10-12-13] pointed out a more pronounced hardening and associated embrittlement of the materials during the early stages of the aging process (up to $1000 \mathrm{~h}$ for the Ti 17 alloy aged at $450^{\circ} \mathrm{C}$ ) before a saturation for longer times. Assuming that these kinetics were similar to precipitation kinetics of intermetallic phases such as $\mathrm{Ti}_{3} \mathrm{Al}$, Shamblen [14] proposed an approach directly relating the decrease in toughness in aged titanium alloys with the volume fraction of precipitates. This approach, resumed by the Wert-Zener equation [14-16] will be applied to previous data to propose a description of embrittlement kinetics as well as time-temperature equivalencies.

\section{Material and experiments}

The Ti 17 alloy used in this work was provided by Aubert \& Duval France, Inc. Its initial microstructure consists in prior $\beta$ grains of $0.5 \mathrm{~mm}$ in the forging direction and about $1.5 \mathrm{~mm}$ in the direction perpendicular to the previous one. Inside the prior $\beta$ grains delimited by grain boundary $\alpha_{\mathrm{GB}}$ phase which form continuous layers, alpha lamellae were found to form a basketwave microstructure. This microstructure is detailed elsewhere [10]. 
A part of the Ti 17 alloy has been spared in order to characterize the reference mechanical behavior in the as-received state. Another part was then aged up to $10000 \mathrm{~h}$ at temperatures ranging from $400^{\circ} \mathrm{C}$ to $500^{\circ} \mathrm{C}$ in an air furnace. After aging, the samples for mechanical tests were prepared using electrical discharge machining.

In-situ tensile tests were conducted using micro-tensile specimen, with a gage length of $10 \mathrm{~mm}$, a gage width of $2 \mathrm{~mm}$ and a thickness of $1 \mathrm{~mm}$. The surfaces of these micro-samples were polished up to 1 micron and then mirror finished using a solution of colloidal silica enriched in $\mathrm{H}_{2} \mathrm{O}_{2}$ to ensure both mechanical polishing and chemical etching. The planarity of the samples was thoroughly controlled with a micrometer to ensure that the difference in thickness between the extremities and the reduced section area was less than 10 microns.

To perform in-situ tensile tests under SEM, the samples were positionned on a Deben $5 \mathrm{kN}$ tensile stage, centered and mechanical backlashes were removed. Reference zones in the center and at two extremities of the sample were selected to enable strain calculation. For each test, eight observation zones were selected to capture both intragranular and intergranular areas, with a regular spacing of $200 \mu \mathrm{m}$ between each zone. A displacement rate of $2 \times 10^{-2} \mathrm{~mm} / \mathrm{min}$ was applied and load steps of $50 \mathrm{MPa}$ in amplitude were chosen to follow the evolution of deformation, with finer increments near the final fracture.

For fatigue crack growth tests, CT40 compact tension specimen were machined according to the ASTM E647-05 [17] specifications $(\mathrm{W}=40)$. Pre-cracking was operated at $\Delta \mathrm{K}=6 \mathrm{MPa} \times \mathrm{m}^{1 / 2}$ by adjusting the loading after each pre-cracking increment, whereas crack growth tests were operated at constant load amplitude, at a frequency of $20 \mathrm{~Hz}$ and a load ratio of $\mathrm{R}=0.1$. Crack propagation experiments were conducted according to the ASTM E647-05 specifications, using the direct current potential drop technique to measure the crack advance, under laboratory air at room temperature.

After testing, systematic observations of the fracture surfaces of the samples were conducted, either using a Talysurf CCI interferometric microscope or a Jeol 6400 SEM with an operating acceleration voltage of $25 \mathrm{kV}$.

\section{$\underline{\text { Results }}$}

In-situ tensile tests

The tensile stress-strain curves for in-situ tensile tests are provided in Figure 2. The results indicate an important loss in ductility after aging, with a total elongation decreasing from $6.8 \%$ for the as-received material to $1.8 \%$ after aging $10000 \mathrm{~h}$ at $450^{\circ} \mathrm{C} . \mathrm{A}$ hardening is also noticed, with an increase in fracture stress from $990 \mathrm{MPa}$ to $1080 \mathrm{MPa}$, for the as-received material and aged material respectively. These data are shown on Table 1 and confirm the tendencies reported in earlier studies referenced in the introduction section. 


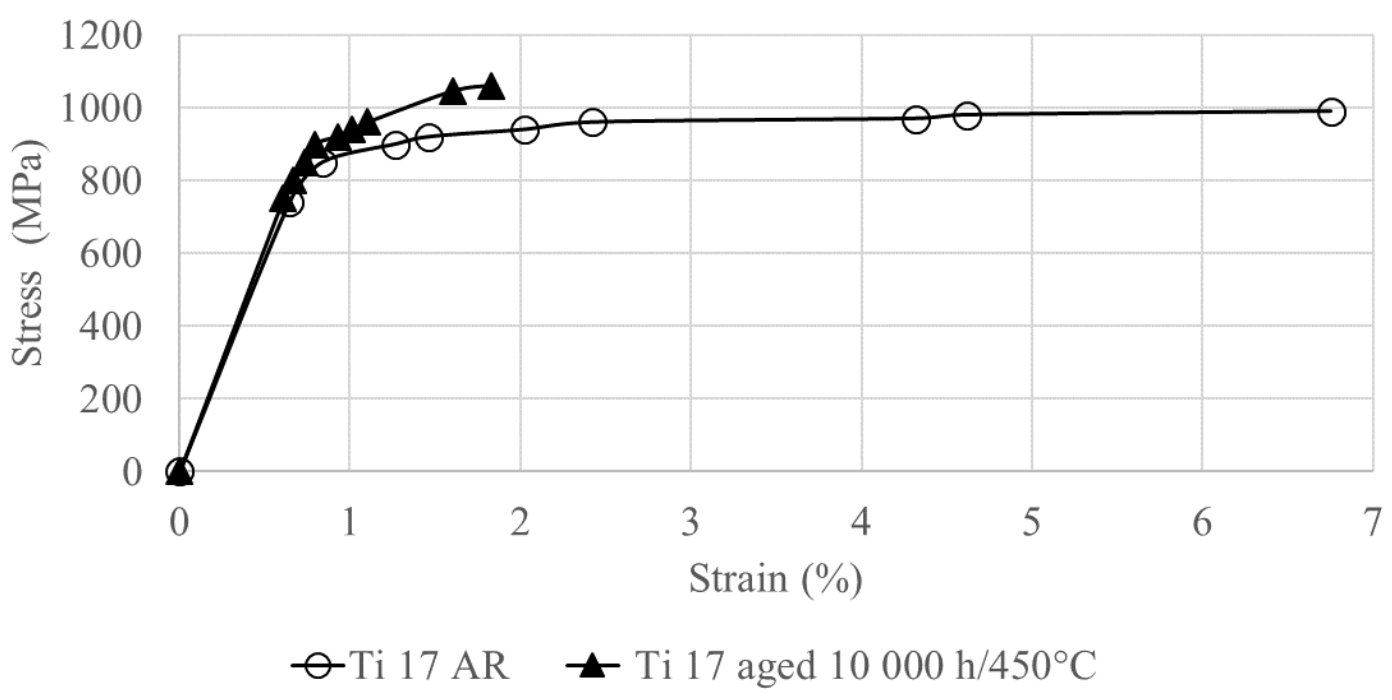

Figure 2: tensile stress-strain curves of the in-situ tensile tests under SEM, for as-received (AR) and aged samples

Table 1: data of the in-situ tensile tests for the as-received and aged samples

Aging time at $450^{\circ} \mathrm{C}$

(h)
Fracture stress

(MPa)
Total elongation

(\%)
As-received (AR)

10000
990

1080
6.8

1.8

The Figure 3 shows the fracture surfaces of both in-situ samples. A strong reduction in section is observed for the as-received sample, with a clearly distinguishable necking shown in Figure 3.a. The fracture proceeds in a ductile way with the formation of dimples as shown in Figure 4.a. For the material aged $10000 \mathrm{~h}$ at $450^{\circ} \mathrm{C}$ however, an evolution to a less deformed, more flat fracture surface with a limited reduction in section area is observed on Figure 3.b. The fracture initiation site is furthermore indicated with dotted lines, as well as the crack propagation direction shown with arrows. The strain localization with a limited plastic deformation reported earlier [10] is here remarkable, as well as the characteristic lamellae decohesion markings shown in Figure 4.b. The size and the disposition of these markings form the same pattern as the entanglement of lamellae constitutive of the basketwave microstructure of the studied Ti 17. 


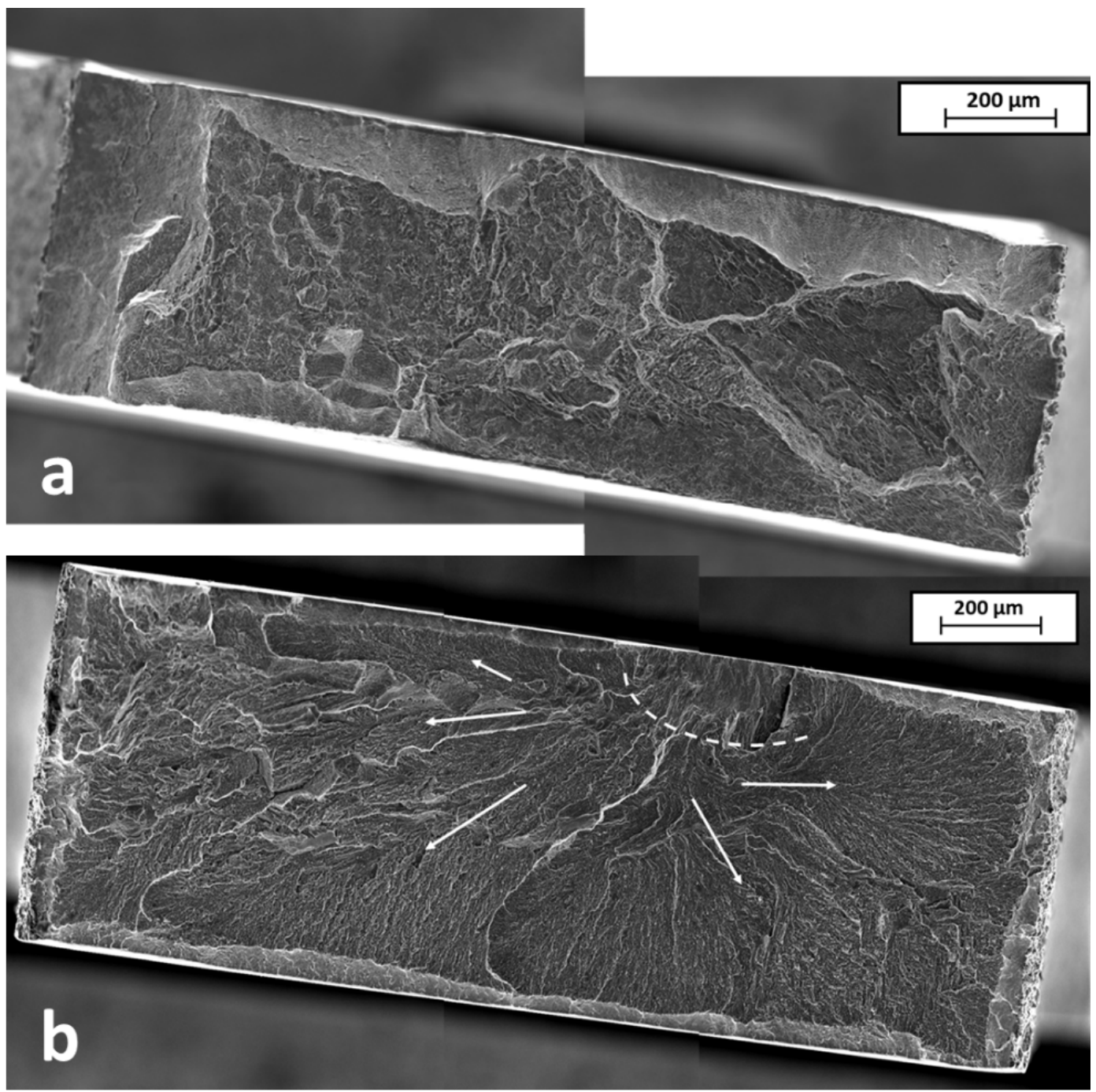

Figure 3: SEM observations of the fracture surfaces of the a) as-received, b) aged $10000 \mathrm{~h} / 450^{\circ} \mathrm{C}$ samples 

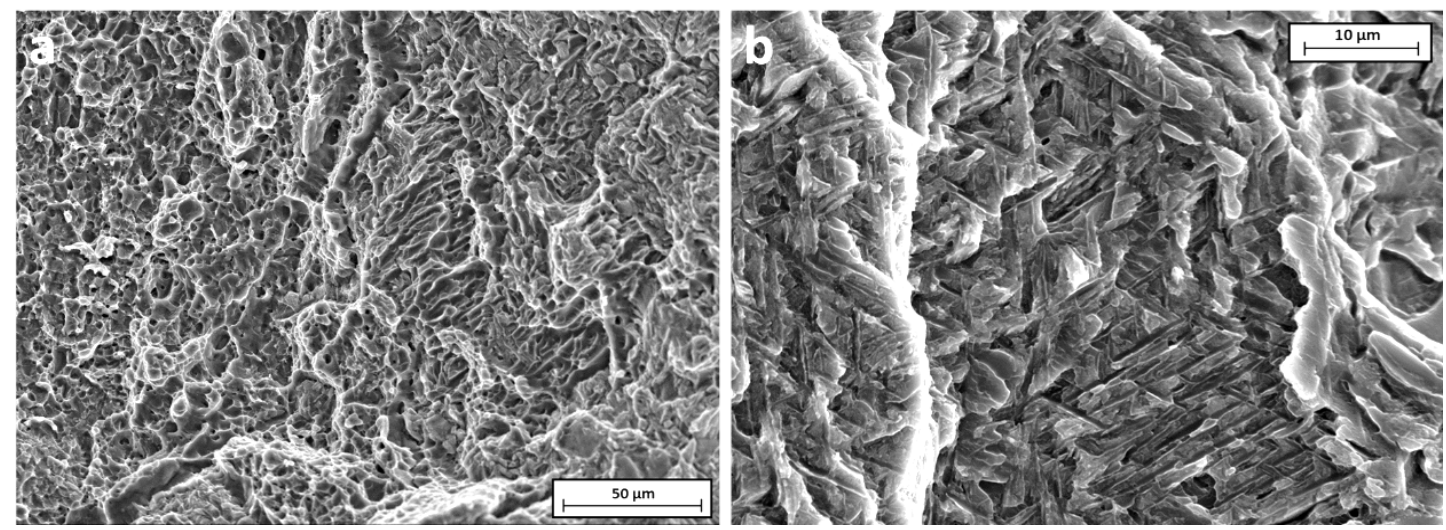

Figure 4: SEM observations of a) dimples on the as-received material, b) lamellae decohesion markings for the material aged $10000 \mathrm{~h}$ at $450^{\circ} \mathrm{C}$

To follow the evolution of the deformation during in-situ tensile tests, some intergranular zones containing grain boundary $\alpha_{\mathrm{GB}}$ phase and intragranular zones focusing on the behavior of individual $\alpha$ lamellae were identified. The Figure 5 shows the observations of these zones for the as-received material, at the first stress increment $(740 \mathrm{MPa})$ and at the stress level before final fracture (980 MPa). Concerning the intergranular zone (Figure 5.a and Figure 5.c), the progressive apparition of slip bands (materialized by white and dark contrasts) within $\alpha$ lamellae and $\alpha_{\mathrm{GB}}$ phase as the stress level increases is shown by arrows. The strain is seen to be mainly accommodated by the intergranular $\alpha_{\mathrm{GB}}$ phase, with the grain B sliding relatively to the grain $\mathrm{A}$ along the $\alpha_{\mathrm{GB}}$ layer as shown on Figure 5.c.

The same comparison has been done for intragranular zones (Figure 5.b and Figure 5.d). At 980 MPa, the Figure 5.d shows the presence of slip traces parallel to each other, oriented perpendicularly to the loading direction. These slip traces propagate through microstructural boundaries such as $\beta$ matrix/ $\alpha$ lamellae interfaces and are not contained within individual lamellae. 


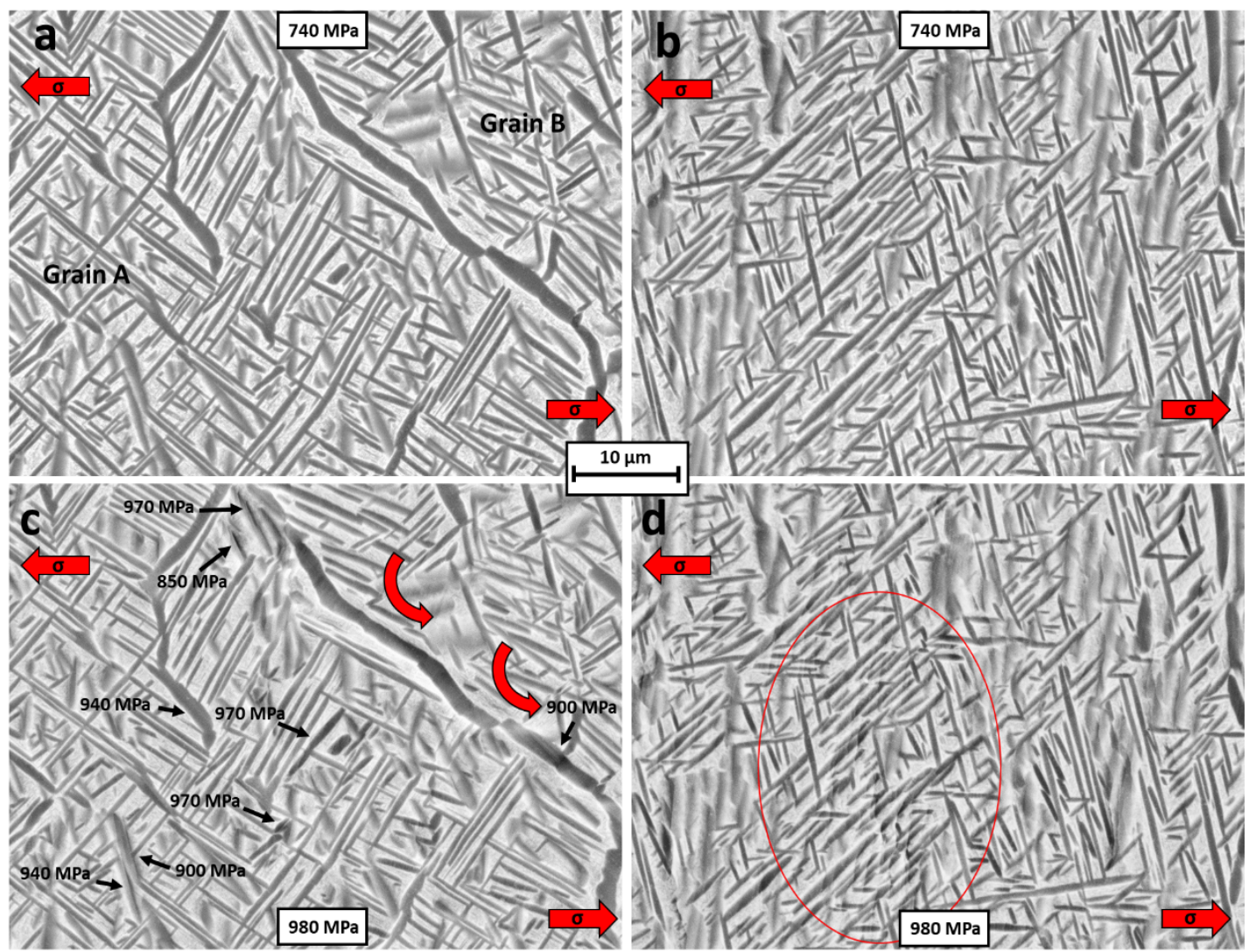

Figure 5: observations of the as-received sample during in-situ tensile tests a) $740 \mathrm{MPa}$, intergranular zone, b) $740 \mathrm{MPa}$, intragranular zone, c) $980 \mathrm{MPa}$, intergranular zone, d) $980 \mathrm{MPa}$, intragranular zone

The Figure 6 shows the observations made on the material aged $10000 \mathrm{~h}$ at $450^{\circ} \mathrm{C}$ during in-situ tensile tests. Significantly fewer plastic activity is detected in intergranular zones (Figure 6.a and Figure 6.c) compared to similar observations made on the as-received material. In the aged material, the slip bands do not cross the microstructural barriers as observed in the as-received case but remain confined within lamellae (Figure 6.b and Figure 6.d). The decreased plastic activity observed in the observed zones should however be weighed by the fact that the strain is strongly localized in the case of the aged material. Even though the final fracture occurs in the vicinity of the observation zones, these zones do not show the evidence of intense plastic activity as the strain is not generalized similarly to the as-received material. Thus, slip bands could have appeared earlier in the loading history of the sample, even if in the observation zones, no deformation could be detected. 


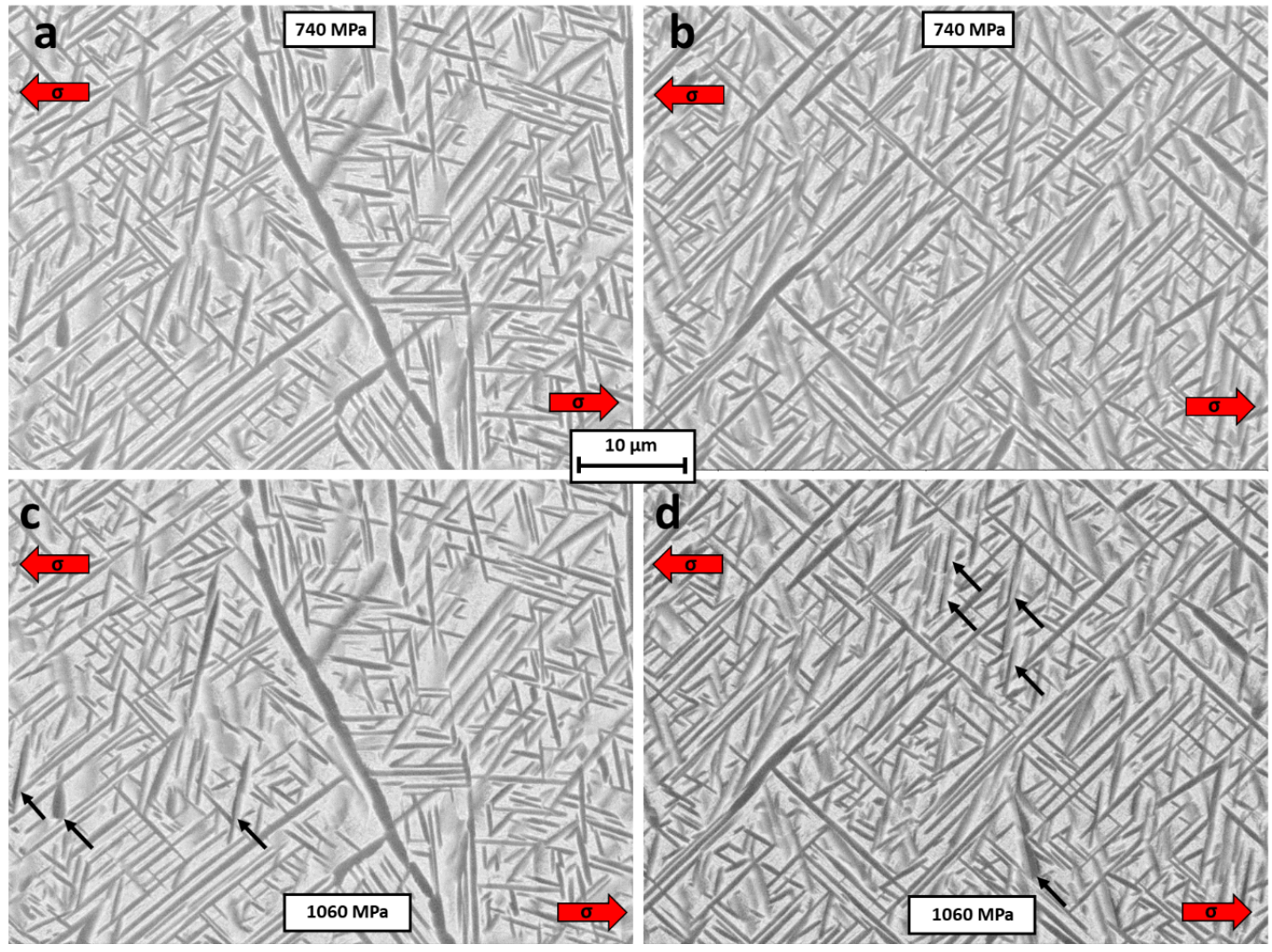

Figure 6: observations of the sample aged $10000 \mathrm{~h}$ at $450^{\circ} \mathrm{C}$ during in-situ tensile tests a) $740 \mathrm{MPa}$, intergranular zone, b) $740 \mathrm{MPa}$, intragranular zone, c) $1060 \mathrm{MPa}$, intergranular zone, d) $1060 \mathrm{MPa}$, intragranular zone

To emphasize the previous observations, the Figure 7 presents the deformation on as-received and aged samples after fracture, on the same area as the zones followed during in-situ tests. The as-received material shown in Figure 7.a confirms the important role of the $\alpha_{\mathrm{GB}}$ phase in the strain-accommodation process. This phase is predominantly deformed as shown with arrows, while the central grain seems less deformed than the surrounding ones. A heterogeneity of deformation between grains is thus remarkable, which can be attributed to the anisotropy in the crystallographic orientation of the $\beta$ phase [18]. The grains with a $\beta$ phase oriented in the $<001>$ direction relatively to the loading direction were seen to be preferentially deformed, up to 10 times more than grains oriented in the $<111>$ direction relatively to the loading direction [18].

The Figure 7.b shows the slip bands within lamellae appearing in sharp contrast in the aged material. At this level of deformation (after fracture), the lamellae appear to be sheared by these intense slip bands occuring mainly at the core of the lamellae and sometimes at the interface between the $\beta$ matrix and the $\alpha$ lamellae. This shearing could be identified as the first step leading to the formation of the $\alpha$-lamellae decohesion markings. This analysis will be further detailed in the discussion section. The $\alpha_{\mathrm{GB}}$ phase does not appear as the preferentially deformed phase anymore, as a competition seems to develop between interfacial $\alpha_{\mathrm{GB}}$ damaging and intralamellar $\alpha$-lamellae damaging. 

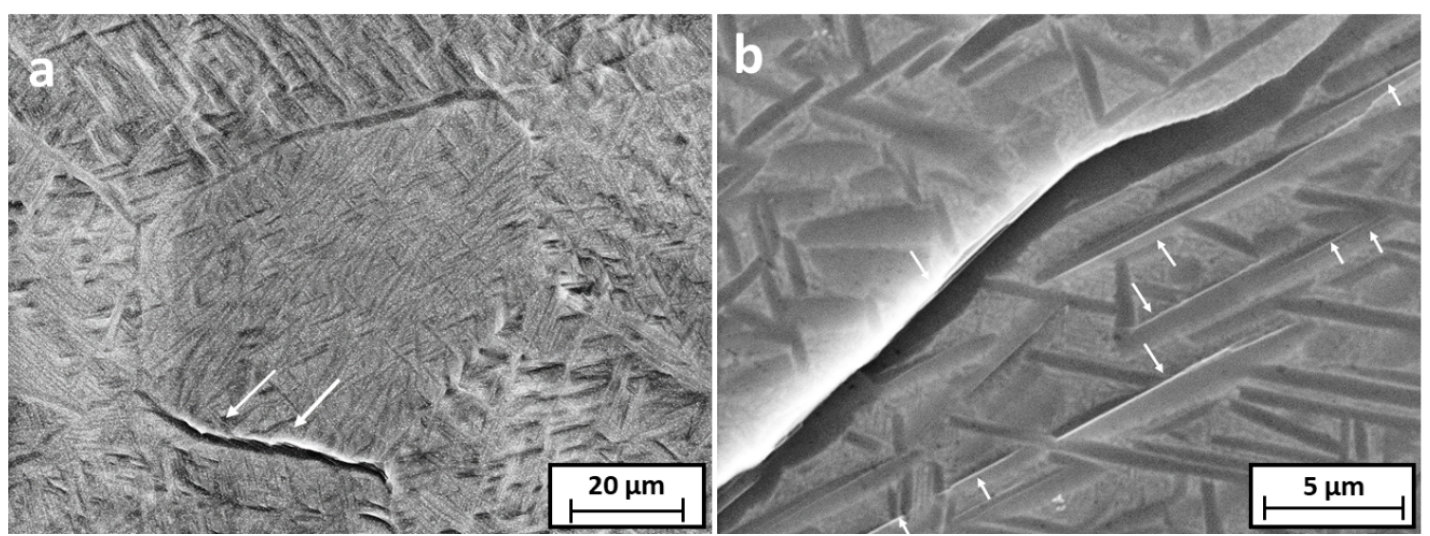

Figure 7: observations carried out on the in-situ samples after fracture, a) as-received material showing a strong deformation of the $\alpha_{\mathrm{GB}}$ phase, b) material aged $10000 \mathrm{~h} / 450^{\circ} \mathrm{C}$ showing the localization of slip bands within alpha lamellae and $\alpha_{\mathrm{GB}}$ phase

Fatigue crack growth tests for different aging conditions

The results of fatigue crack growth tests performed for different aging conditions are shown in Figure 8. As reported in a previous communication [10], aging causes an increase in fatigue crack growth rates $\mathrm{da} / \mathrm{dN}$ once a critical value of the stress intensity factor range $\Delta \mathrm{K}_{\mathrm{cr}}$ is reached for a fixed value of the load ratio $\mathrm{R}$ ( $\mathrm{R}=0.1$ in this work). It has then been shown that this increase in crack growth rates was related to the static component $\mathrm{K}_{\max }$ of the loading [10], reported as $\mathrm{K}_{\mathrm{cr}}$ in this work. The values of both $\Delta \mathrm{K}_{\mathrm{cr}}$ and $\mathrm{K}_{\mathrm{cr}}$ for the different aging conditions are given on Table 2. 


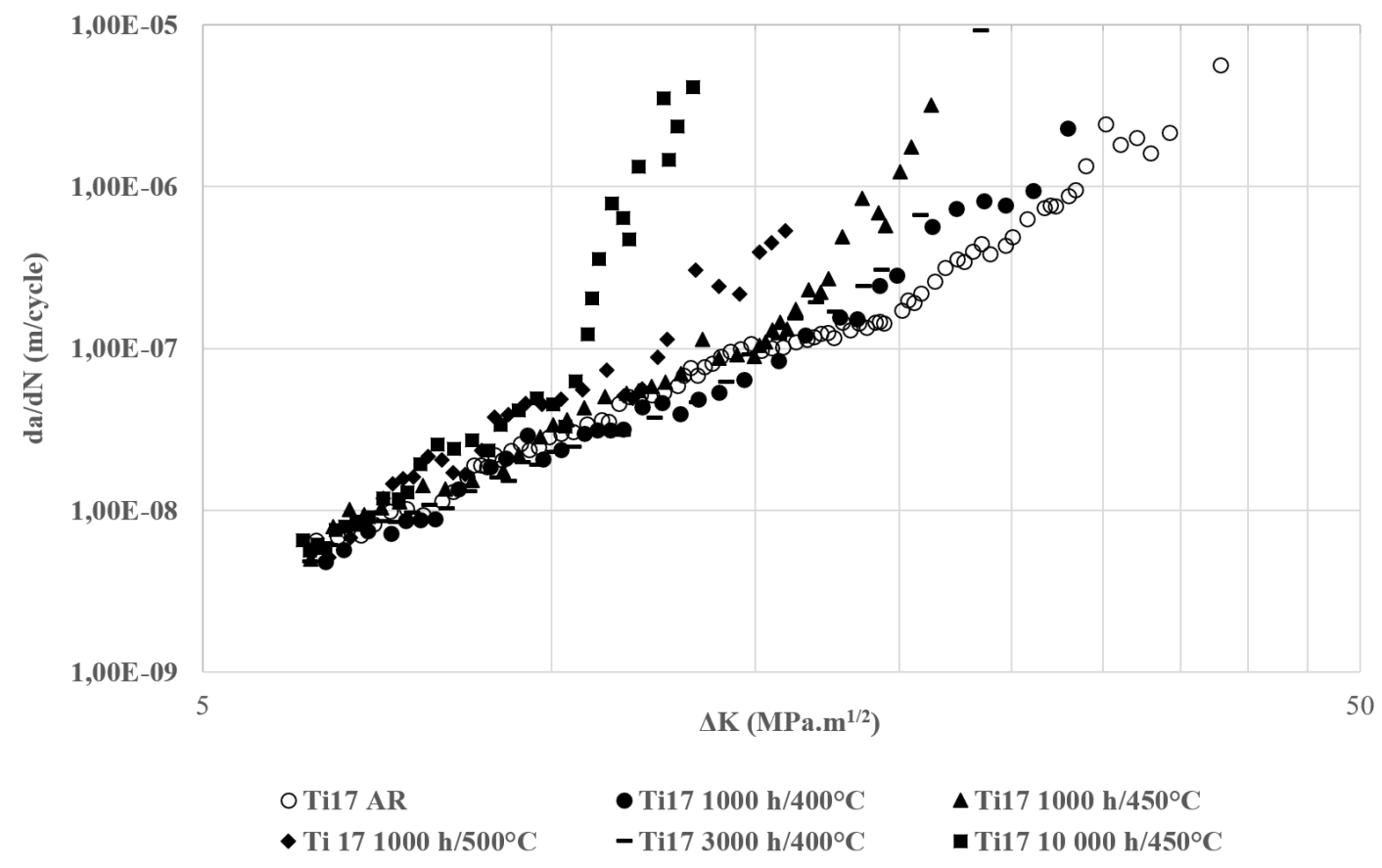

Figure 8: fatigue crack growth curves for materials aged under different time/temperature conditions (tests at room temperature under lab air)

Table 2: $\Delta K_{\mathrm{cr}}$ and $\mathrm{K}_{\mathrm{cr}}$ values for the different aging conditions studied in this work. The data shown with the * symbol were provided by Airbus Group Innovations

\begin{tabular}{|ccc|}
\hline $\begin{array}{c}\text { Aging condition } \\
\text { (time/temperature })\end{array}$ & $\begin{array}{c}\Delta \mathrm{K}_{\mathrm{cr}} \text { for } \mathrm{R}=0.1 \\
\left(\mathrm{MPa} \cdot \mathrm{m}^{1 / 2}\right)\end{array}$ & $\begin{array}{c}\mathrm{K}_{\mathrm{cr}} \text { for } \mathrm{R}=0.1 \\
\left(\mathrm{MPa} \cdot \mathrm{m}^{1 / 2}\right)\end{array}$ \\
\hline As-received AR & $\Delta \mathrm{K}_{\text {final }}=38$ & $\mathrm{~K}_{\text {max,final }}=42$ \\
$1000 \mathrm{~h} / 400^{\circ} \mathrm{C}$ & $27 \pm 1^{*}$ & $30^{*}$ \\
& &
\end{tabular}


$3000 \mathrm{~h} / 400^{\circ} \mathrm{C}$

$6000 \mathrm{~h} / 400^{\circ} \mathrm{C}$

$10000 \mathrm{~h} / 400^{\circ} \mathrm{C}$

$1000 \mathrm{~h} / 450^{\circ} \mathrm{C}$

$10000 \mathrm{~h} / 450^{\circ} \mathrm{C}$

$1000 \mathrm{~h} / 500^{\circ} \mathrm{C}$
$16 \pm 1$

$15 \pm 1 *$

$15 \pm 1 *$

$15 \pm 1$

$10 \pm 1$

$12 \pm 1$
18

$17 *$

$17^{*}$

13

The results of these crack growth tests confirm the first statements concerning a strong decrease in mechanical properties during the first stages of aging, before a saturation of this phenomenon for longer times. For the specific temperature of $400^{\circ} \mathrm{C}$, the embrittlement of the material evidenced by the decrease in the $\mathrm{K}_{\mathrm{cr}}$ values seems to saturate after $3000 \mathrm{~h}$ of exposure with no significant evolution up to $10000 \mathrm{~h}$.

At this stage, even if the increase in fatigue crack growth rates are not of the same intensity for all aging conditions, some time/temperature equivalencies can be identified based on the $\mathrm{K}_{\mathrm{cr}}$ values. Indeed, aging $6000 \mathrm{~h}$ at $400^{\circ} \mathrm{C}$ produces the same $\mathrm{K}_{\mathrm{cr}}$ decrease as aging $1000 \mathrm{~h}$ at $450^{\circ} \mathrm{C}$, whereas the same $\mathrm{K}_{\mathrm{cr}}$ decrease reached after aging $10000 \mathrm{~h}$ at $450^{\circ} \mathrm{C}$ can roughly be achieved after only $1000 \mathrm{~h}$ at $500^{\circ} \mathrm{C}$. Thus, the aging temperature seems to have a greater impact on the decrease in mechanical properties than the exposure time. For a given time/temperature condition, the exposure to a temperature increased of only $50^{\circ} \mathrm{C}$ can reduce the exposure time of thousands of hours to achieve the same decrease in mechanical properties. These time temperature equivalencies, as well as the temperature-activated nature of the embrittling phenomenon will further be discussed in the discussion section.

\section{$\underline{\text { Discussion }}$}

The in-situ tensile tests have evidenced an important change in the damage mechanisms in the aged material, compared to the asreceived reference material. Firstly, the absence of dimples on the fracture surface of the aged sample is consistent with the loss in ductility due to aging. The deformation, while being majorly accommodated by the ductile $\alpha_{\mathrm{GB}}$ in the as-received material, becomes highly localized at the scale of $\alpha$ lamellae. This phenomenon was identified as the origin of the loss of generalized plasticity at a macroscopic scale, giving rise to an intense strain confinement at the vicinity of the crack tip. This fact is further illustrated on Figure 9, which shows observations made with an interferometric microscope on both as-received and aged fatigue crack growth samples. The interferometric microscope provides a color map of the variations in depth levels induced by the plastic wake that develops at the crack tip during the crack propagation (lateral displacement illustrated on Figure 9). It can be observed in the as-received material that the plastic deformation left by the crack wake increases continuously and expands progressively around the crack propagation line with increasing crack lengths. For the material aged $10000 \mathrm{~h}$ at $450^{\circ} \mathrm{C}$ however, the development of this plastic deformation loses totally its continuous and expansive character. A pronounced strain localization is visible in the extreme vicinity of the crack propagation line and a fracture with a limited plasticity occurs, expressing a loss of ductility and an embrittlement of the material. 


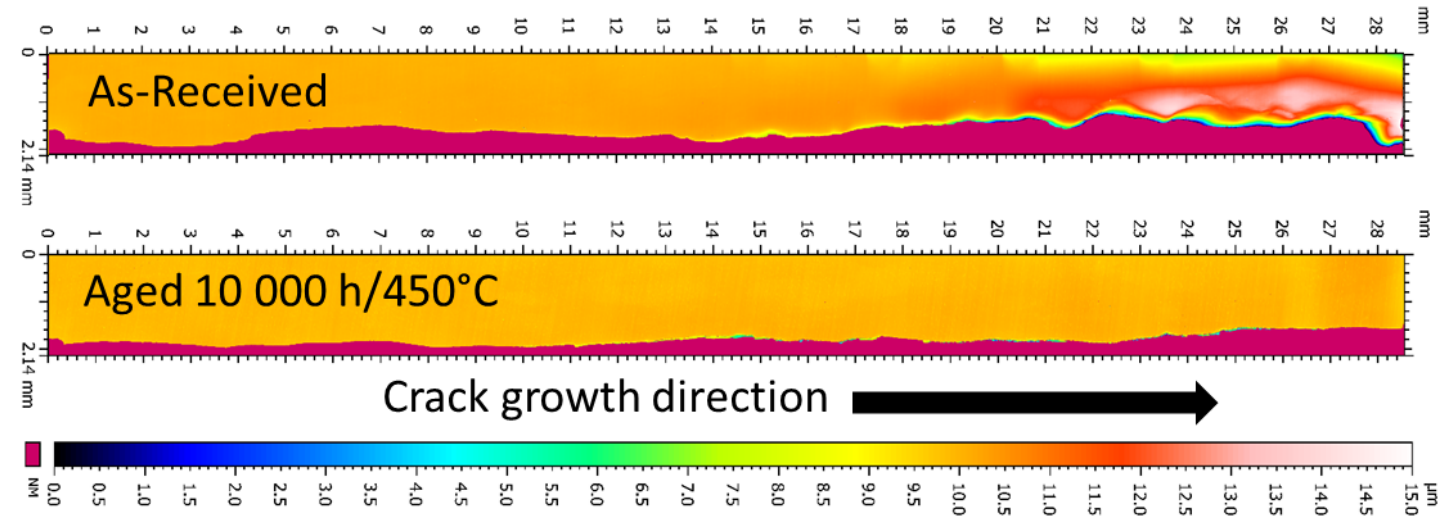

Figure 9: mapping of the lateral displacement in the crack wake, for the as-received and aged materials. Observations performed on fatigue crack growth samples after fracture, by means of an interferometric microscope.

The role of intragranular $\alpha$ lamellae, that was minor in the as-received state, becomes significant after aging. On the other hand, the $\alpha_{\mathrm{GB}}$ phase does not seem to be able to express its ductile character (disparition of dimples) and its strain-accommodating function. This change could on the one hand be attributed to a modification of the cohesive strength of the $\alpha_{\mathrm{GB}}$ phase after metallurgical transformations induced by aging, such as $\mathrm{Al}$ depletion of the matrix due to $\mathrm{Ti}_{3} \mathrm{Al}$ precipitation [11]. On the other hand, the fracture occurs at an earlier stage in the aged material compared to the as-received case. This premature fracture could prevent the material to reach sufficient strain levels enabling the expression of the strain-accomodating function of the $\alpha_{\mathrm{GB}}$ phase.

A competition is then set between an interfacial damage mechanism in the case of the intergranular $\alpha_{\mathrm{GB}}$ phase, and a damage mechanism involving the shear and the breakage of intragranular $\alpha$ lamellae. Due to the higher volume density of $\alpha$ lamellae in the material, this competition would proceed according to the latter mechanism occurring at the core of $\alpha$ lamellae and in multiple sites inside the aged material. The resulting fracture produces a globally transgranular, flat surface with limited plasticity and generates the characteristic $\alpha$ lamellae decohesion markings. Rather than the term "decohesion", the $\alpha$ lamellae markings seem to result from a breakage at the core of lamellae, occurring in three steps as illustrated in Figure 10. The occurrence of this damage mechanism in three steps is further supported by observations carried out on the in-situ sample referring to the material aged $10000 \mathrm{~h}$ at $450^{\circ} \mathrm{C}$, also shown in Figure 10. The observation of an area near the fracture surface shows the evidence of the breakage of lamellae at different damaging stages, marked from 1 to 3 near the relevant features. 


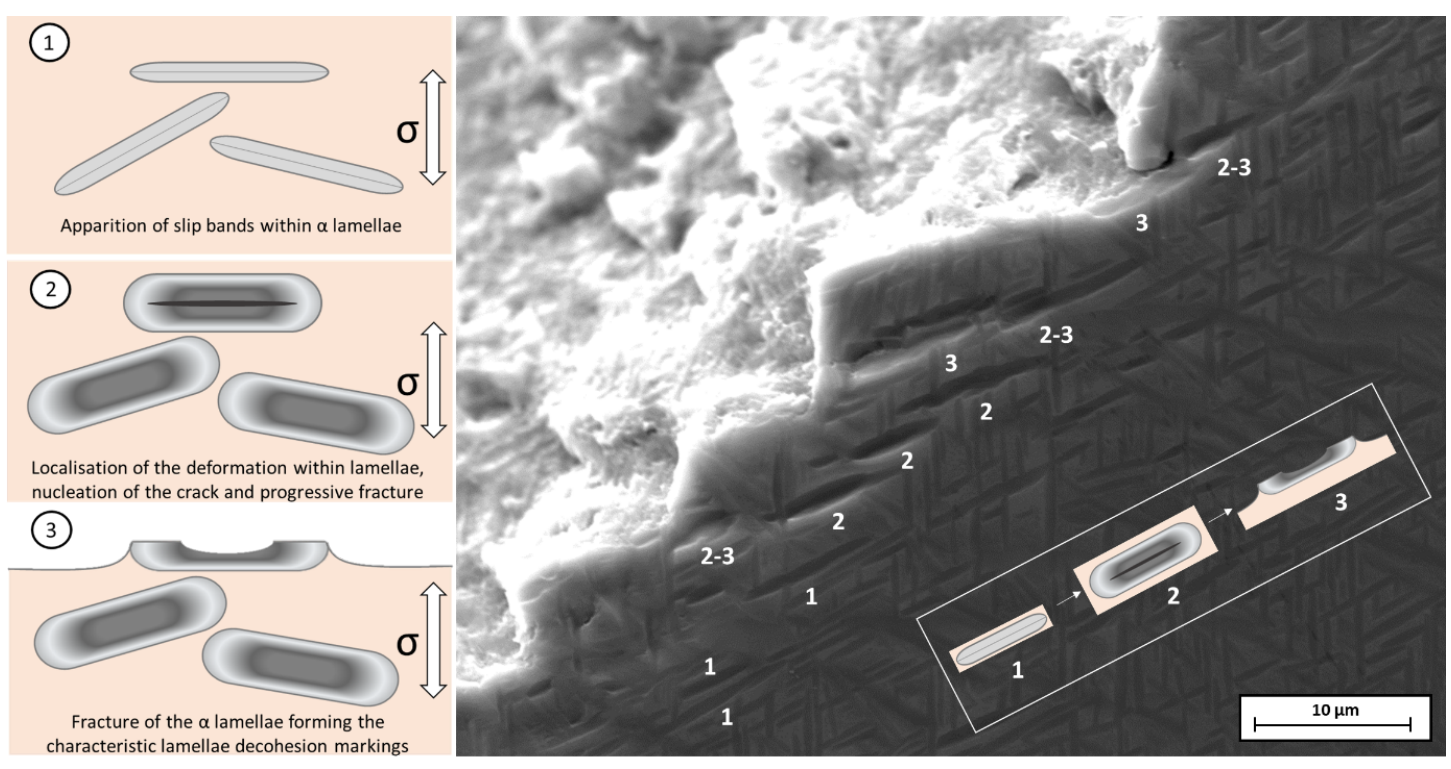

Figure 10: left) schematics of the damage mechanism occurring inside $\alpha$ lamellae after aging, right) observation of an area near the fracture surface for the in-situ tensile sample of the material aged $10000 \mathrm{~h} / 450^{\circ} \mathrm{C}$, confirming the previous damage mechanism

The modification of the damage mechanism and mechanical properties developed previously are closely related to metallurgical transformations induced by aging. The precipitation of intermetallic phases, mainly the $\mathrm{Ti}_{3} \mathrm{Al}$ phase has been extensively reported in the literature mentioned in the introduction section. Based on these observations, Shamblen [14] studied the loss in toughness in Ti6242 and Ti5621S titanium alloys, aged between $426{ }^{\circ} \mathrm{C}$ and $593^{\circ} \mathrm{C}$ up to $5000 \mathrm{~h}$. Assuming that the embrittlement was mainly attributed to $\mathrm{Ti}_{3}(\mathrm{Al}, \mathrm{Sn})$ phases, the authors proposed that the embrittlement degree of the material after a certain aging time $t$ was proportional to the volume fraction $\mathrm{X}_{\mathrm{t}}$ of precipitates. The kinetics of such solid-state transformations involving the nucleation and growth of precipitates is described by the Kolmogorov-Johnson-Mehl-Avrami model [19] which particular solution for isothermal conditions is given by the Wert-Zener equation [14-16]:

$$
X_{t}=1-\exp \left[-(t / \tau)^{m}\right]
$$

With $\tau$ the characteristic or relaxation time and $\mathrm{m}$ a time-constant, dependent on the transformation mechanisms and the shape of the precipitates. In the work of Shamblen as well as in the present work, the value of $m$ is assumed to be constant for all temperatures, for a given alloy.

In the present work, the embrittlement kinetics will be analyzed considering the $\mathrm{K}_{\mathrm{cr}}$ values of the Table 2 . The analysis of these values allows to calculate for a given aging temperature, the embrittlement degree $\mathrm{X}$ 't after a given aging time t:

$$
\mathrm{X}^{\prime} \mathrm{t}=\left(\mathrm{K}_{\max , \text { as-received }}-\mathrm{K}_{\mathrm{cr}, \mathrm{t}}\right) / \mathrm{K}_{\max \text {, as-received }}
$$

According to the work of Shamblen [14], X't obeys to the Wert-Zener equation shown in equation (1). The value of the timeconstant $\mathrm{m}$ was obtained for the Ti 17 alloy after linearization of equation (1). The analysis of data available in Table 2 for aging operated at $400^{\circ} \mathrm{C}$ provides a value of $\mathrm{m}=0.44$ for the $\mathrm{Ti} 17$ alloy, which is consistent with the value reported by Shamblen of 0.41 for the two alloys of the study. The value of $\mathrm{m}$ seems independent from the composition of the alloy [14] and depends mainly on the embrittling mechanism which is believed to be similar between Ti 17, Ti 6242 and Ti 5621S alloys, i.e. the 
precipitation of $\mathrm{Ti}_{3}(\mathrm{Al}, \mathrm{Sn})$ phases. Knowing the value of $\mathrm{m}$, the parameter $\tau$ was then calculated for all aging temperatures of Table 2. The results are given in Table 3.

Table 3: relaxation times $\tau$ calculated for the aging temperatures of the present work

\begin{tabular}{cc}
\hline Temperature $\left({ }^{\circ} \mathrm{C}\right)$ & Relaxation time $\tau(\mathrm{h})$ \\
400 & 8449 \\
450 & 2536 \\
500 & 694
\end{tabular}

Assuming that the precipitation of $\mathrm{Ti}_{3}(\mathrm{Al}, \mathrm{Sn})$ phase, thus the embrittlement of the materials studied was a thermally activated phenomenon, an activation energy for the embrittlement was calculated. Supposing $\tau$ to be inversely proportional to the diffusion coefficient of elements in solid solution in the studied alloys, $\tau$ can be expressed with an Arrhenius type equation as follows:

$$
1 / \tau=\mathrm{A} \exp (-\mathrm{Q} / \mathrm{RT})
$$

With A a constant, Q the precipitation activation energy including the energies of both nucleation and growth of precipitates [14], $\mathrm{R}$ the ideal gas constant and $\mathrm{T}$ the temperature in kelvins. The analysis of the data given in Table 3 allow to calculate the activation energy for the Ti 17 alloy, of $107,9 \mathrm{~kJ} / \mathrm{mol}$ i.e. $25,8 \mathrm{kcal} / \mathrm{mol}$. This value is consistent with the values given in the work of Shamblen, of $25 \mathrm{kcal} / \mathrm{mol}$ for the Ti6242 and $28 \mathrm{kcal} / \mathrm{mol}$ for the Ti $5621 \mathrm{~S}$. These results are resumed on Table 4 . These energies are close to diffusion energies of aluminium and tin in the $\beta$ phase reported by Goold [20], thus justifying the dependence of the embrittling phenomenon to the $\mathrm{Ti}_{3}(\mathrm{Al}, \mathrm{Sn})$ phase precipitation. Some other studies [21-22] reported higher energies for the diffusion of aluminium in the $\beta$ phase, ranging from 150 to $332 \mathrm{~kJ} / \mathrm{mol}$ i.e. 36 to $79 \mathrm{kcal} / \mathrm{mol}$. Räisänen [23] further reported the diffusion activation energy of $\mathrm{Al}$ in a $\alpha$-Ti alloy, of $1.62 \mathrm{eV} / \mathrm{atom}$ i.e. $37 \mathrm{kcal} / \mathrm{mol}$. The previous results remain in the order of magnitudes expected for such activation energies.

Table 4: precipitation and diffusion activation energies identified in the present work, in [14] and [20]

Alloy grade
Activation energy ( $\mathrm{kcal} / \mathrm{mol})$
Reference
Ti-6Al-2Sn-4Zr-2Mo (Ti 6242)

Ti-5Al-6Sn-2Zr-1Mo-0.25Si (Ti 5621S) 
Ti-5Al-2Sn-2Zr-4Mo-4Cr (Ti 17)

Diffusion $\mathrm{Al} \rightarrow \mathrm{Ti}_{\beta}$

Diffusion $\mathrm{Sn} \rightarrow \mathrm{Ti}_{\beta}$
25,8

25,5

28
This work

To conclude the discussion on the analysis of the embrittlement kinetics, the results produced in this work as well as the data extracted from the work of Shamblen were reported on the so called Wert-Zener plot, representing the remaining fraction of toughness or $\mathrm{K}_{\mathrm{cr}}$ after aging, 1-X't, as a function of the time ratio $t / \tau$. This plot is presented in Figure 11 . It is remarkable that the points of both studies, referring to different materials aged under different conditions fall into a single curve, corresponding to the Wert-Zener equation plotted with dotted lines. This result emphasizes the fact that the embrittlement of the materials studied follow a unique physical mechanism, the precipitation of intermetallic phases.

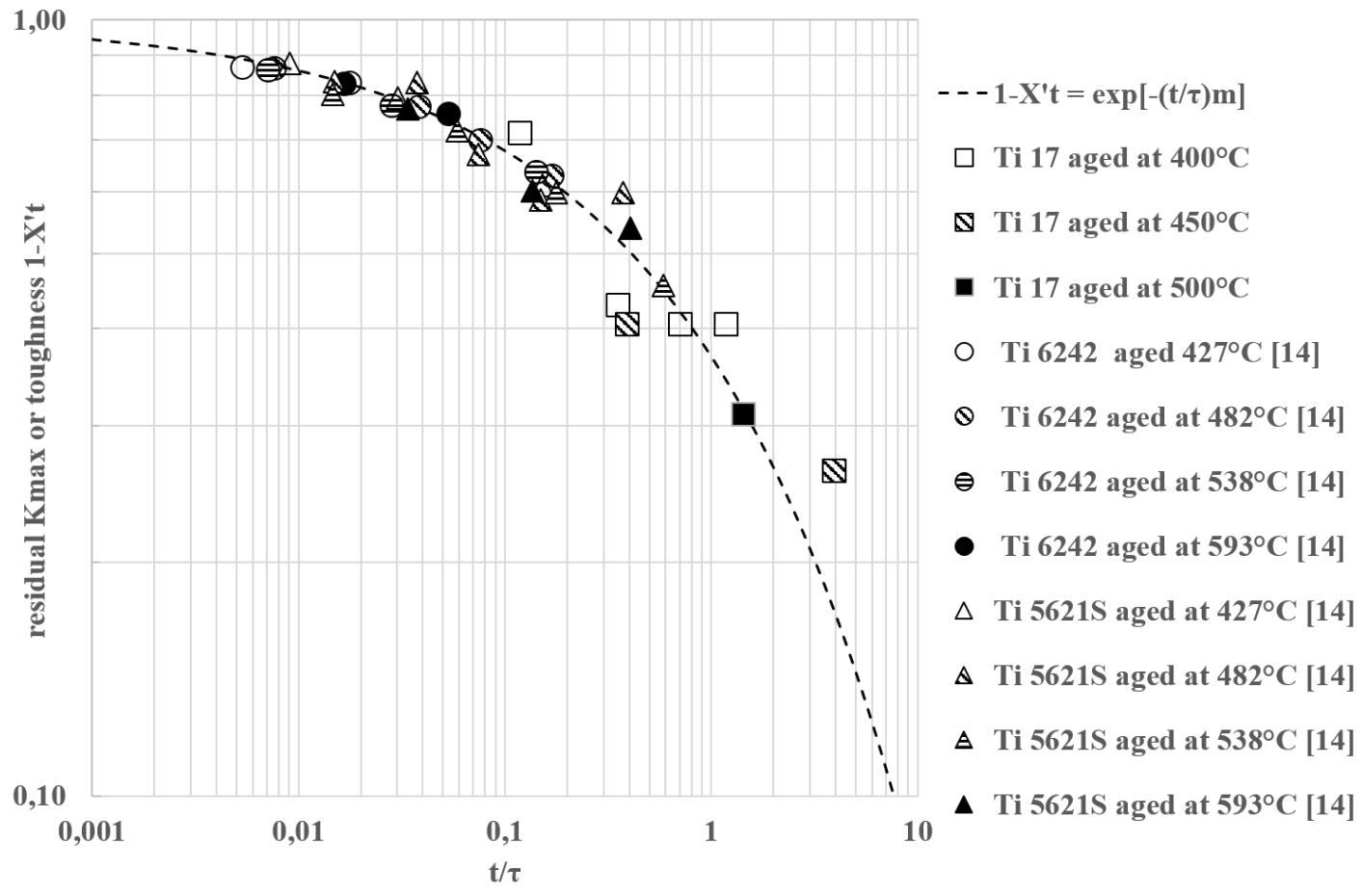

Figure 11: Wert-Zener plot for the data referring to the Ti 17 alloy and the alloys of the work of Shamblen [14]

\section{Conclusion}


This work has provided a deeper understanding of the damage mechanisms leading to the embrittlement of a Ti 17 alloy aged up to $10000 \mathrm{~h}$ at temperature ranging from $400^{\circ} \mathrm{C}$ to $500^{\circ} \mathrm{C}$. The damaging process switches from a mechanism involving a strainaccommodation mainly supported by the ductile $\alpha_{\mathrm{GB}}$ phase prior to aging, to a mechanism involving strain localization within individual $\alpha$ lamellae and their consecutive breakage after aging. A damage mechanism explaining the different steps leading to the formation of lamellae markings characteristic of aging has been consecutively proposed. The translation at a macroscopic scale of this damage mechanism occurring at a microscopic level is the loss of the generalized plastic deformation and an early fracture with limited plasticity. The analysis of the drop in mechanical properties due to aging, based on the precipitation physics of intermetallic phases occurring in such titanium alloys, allowed to provide an expression modelling the embrittlement kinetics thanks to the Wert-Zener equation. The identification of the parameters of the equation for various alloys of the literature and in particular for the Ti 17 alloy studied in this work has been carried out. This identification allowed to propose a model, enabling to predict the embrittlement level consecutive to a specific time/temperature condition, as well as time-temperature equivalencies.

\section{Acknowledgements}

The author gratefully thanks Aubert \& Duval for providing the materials enabling this work, as well as the Agence Nationale de la Recherche for funding this work (convention 2014-00-16) and the partners of the ANR-DUSTI program for the fruitful discussions.

\section{$\underline{\text { References }}$}

[1] J.D. Cotton, R.D. Briggs, R.R. Boyer, S. Tamirisakandala, P. Russo, N. Shchetnikov, J.C. Fanning, Jom 67 (2015) 12811303 .

[2] R.R. Boyer, Mater. Sci. Eng. A 213 (1996) 103-114.

[3] I. Weiss, S.L. Semiatin, Mater. Sci. Eng. A 243 (1998) 46-65.

[4] A.P. Woodfield, P.J. Postans, M.H. Loretto, R.E. Smallman, Acta Metall. 36 (1988) 507-515.

[5] A. Madsen, E. Andrieu, H. Ghonem, Mater. Sci. Eng. A 171 (1993) 191-197.

[6] X. Zhang, D. Evans, W. Baeslack III, H. Fraser, Mater. Sci. Eng. A 344 (2003) 300-311.

[7] A. Madsen, H. Ghonem, Mater. Sci. Eng. A 177 (1994) 63-73.

[8] A. Madsen, H. Ghonem, J. Mater. Eng. Perform. 4 (1995) 301-307.

[9] J. Liu, S. Li, D. Li, R. Yang, Effect of Aging on Fatigue-Crack Growth Behavior of a High-Temperature Titanium Alloy, 2004.

[10] L. Sasaki, G. Hénaff, M. Arzaghi, P. Villechaise, J. Delfosse, Mater. Sci. Eng. A 707 (2017) 253-258.

[11] S. Hémery, P. Villechaise, Scr. Mater. 130 (2017) 157-160.

[12] J.C. Williams, B.S. Hickman, H.L. Marcus, Metall. Trans. 2 (1971) 1913-1919.

[13] A. Gysler, G. Lütjering, V. Gerold, Acta Metall. 22 (1974) 901-909.

[14] C.E. Shamblen, Metall. Trans. 2 (1971) 277-280. 
[15] J.W. Christian, The Theory of Transformations in Metals and Alloys, Newnes, 2002.

[16] H.I. Aaronson, M. Enomoto, J.K. Lee, Mechanisms of Diffusional Phase Transformations in Metals and Alloys, CRC Press, 2016.

[17] ASTM E647-05, (n.d.).

[18] T. Duval, Analyse Multi-Échelles Des Relations Microstructure/Propriétés Mécaniques Sous Sollicitation Monotone et Cyclique Des Alliages de Titane $\beta$-Métastable, ISAE-ENSMA -Poitiers, Phd Thesis, 2013.

[19] J. Farjas, P. Roura, Acta Mater. 54 (2006) 5573-5579

[20] D. Goold, J. Inst. Met. 88 (1960) 444-448.

[21] H. Araki, T. Yamane, Y. Minamino, S. Saji, Y. Hana, S. boo Jung, Metall. Mater. Trans. A 25 (1994) 874876.

[22] G. Neumann, C. Tuijn, Self-Diffusion and Impurity Diffusion in Pure Metals: Handbook of Experimental Data, Elsevier, 2011.

[23] J. Räisänen, A. Anttila, J. Keinonen, J. Appl. Phys. 57 (1985) 613-614. 